\title{
Birds, garden plants and suburban bushlots: where good intentions meet unexpected outcomes
}

\author{
Carla P. Catterall \\ Faculty of Environmental Sciences, Griffith University, Nathan, QId. 4I I I, Australia. \\ Email C.Catterall@griffith.edu.au
}

\begin{abstract}
This paper assesses the effects of vegetation retention and garden planting on birds in the rapidly urbanising greater Brisbane region. Formerly forested areas that are cleared and urbanised show a large reduction in the number of small-bodied species, and a minor increase in the number of introduced species.Very small ( $<5 \mathrm{ha})$ remnants of eucalypt forest also lose small-bodied native birds, and additionally show increases in larger-bodied species. Suburbs that are better-vegetated resemble the very small remnants: they have not re-acquired small-bodied native species, but have more large species. Analyses of individual species' abundances revealed three distinct species groups. "Aussi Icons" are large-bodied, often ground-feeding species, that characterise well-vegetated suburbs and I-2 ha remnants of eucalypt forest ("bushlots"). "New Arrivals" are a group of mixed habits that characterise poorly-vegetated suburban areas."Neglected Foliphiles" are small-bodied, foliage-feeding species that are diverse and common in large eucalypt forest remnants but largely absent from small remnants and well-vegetated suburbs. One species, the noisy miner Manorina melanocephala, is important in aggressively excluding the small foliage-feeding birds from partly-vegetated areas and small bushlots. The abundance of noisy miners was negatively correlated with the number of small-bodied bird species, across all well-vegetated sites, and also within individual types of land cover. Noisy miners occur throughout subtropical and temperate eastern Australia. Planting of scattered eucalypts, small patches, and cultivars of nectar-rich native plant species can encourage noisy miner occupancy, and hence have a different effect on a garden's bird diversity from that intended. I discuss likely avifaunal changes over time, and the implications for land use planning, public education, and spatial scaling in urban design.
\end{abstract}

Key words: conservation, wildlife, forest, Manorina, spatial scale, habitat, planting, restoration

\section{Introduction}

Australian cities house most of the country's human population and it is within the urban environment that most people encounter wildlife, and experience most of their lifetime opportunities for practical learning about them. Although it is less than two centuries since the full establishment of any towns or cities, Australia's urbanised area has expanded rapidly, and development is now occurring along much of the subtropical and temperate coast and adjacent lowlands. It is, therefore, imperative to gain a better understanding of the effects of urbanisation on wildlife in Australian environments. This understanding could enable the creation of locally appropriate methods of urban design that can sustain the heritage variety of native species in areas settled by people. To begin, we need to consider the nature of the urban land cover, how it differs from that pre-settlement, and what this means for wildlife.

Prior to European settlement, land in coastal and subcoastal eastern Australia was almost entirely covered with continuous forest, but is now dotted with towns and cities that sprawl over extensive areas, due to housing allotments that are large relative to those in many other parts of the world. Where there was formerly a nearcontinuous forest canopy of tall trees, above a structurally complex understorey of small trees, shrubs and tall grasses, there is now a substantial proportion of the land area covered by concrete, bitumen, and built structures, together with large gardens that are nutrient-rich and well watered (due to added fertiliser and irrigation), containing mown grassy lawns, sprinkled with scattered small trees and shrubs. Furthermore, the component plant species have undergone great change, with the original trees and shrubs replaced by cultivated species introduced from other parts of the world. The original forest vegetation persists only as small scattered remnants, and has been entirely removed from substantial areas.

The style of land cover within such urban regions may be fairly uniform within areas of hectares to tens of hectares, but at broader scales of tens to hundreds of square kilometers, Australian urban environments are complex spatial mosaics of different forms of land cover, including not only residential suburbs with houses and gardens, but also concrete-dominated business and industrial domains, grassy parklands and golf courses with scattered trees, patches of cropland or remnant cleared pasture, and remnant native forest of different types.

The different land cover types within this broad urban mosaic differ in the quality and quantity of the resources that they provide to wildlife, and when one form of land cover is converted to another, differences among species in resource requirements will create "winners" and "losers" (those species that increase in abundance and those that decrease in abundance), as well as those that appear to be unaffected (see for example Catterall et al. 1998). To avert local declines and extinctions in regions where forest is being converted to 
urban development, or to successfully re-establish species in degraded areas, it would be useful to apply an understanding of these differences in species' responses to the planning and management of urban land cover.

The effects of deforestation and urbanisation have been better documented for avifauna than for any other animal group, and birds are useful ecological indicators (Catterall 1991, Landsberg et al. 1999). They are also a particularly well-appreciated flagship group that provide a source of pleasure and fascination to many people who otherwise have no special interest in nature (Catterall 1991). Many people like to feel that they are building or maintaining gardens that are attractive to native birds, and which help support them.

Promotional and educational materials about Australian urban wildlife have frequently focused on the issue of providing specific resources used by Australian birds, such as planting trees or shrubs with flowers that contain abundant nectar for honeyeaters. The horticultural industry has capitalised on this, and the label "bird attracting" has been used to persuade home gardeners to purchase cultivars of native plants such as Grevillea, Eucalyptus and Callistemon. Government and non-government organisations interested in wildlife conservation have also promoted the notion of "creating a wildlife-friendly garden" by installing individual plant specimens of selected native species as a means of "providing a home for native fauna". Furthermore, business groups engaged in commercially-based urban construction projects, when faced with opposition from conservationists, extend this approach by proposing to plant native tree and shrub specimens within developments. These views invoke a faith that urban tree planting can offset the destruction of large areas of indigenous forest and woodland habitat, and perhaps ease a person's feeling of concern and anxiety about being unable to halt widespread ecological degradation.

For example, in September 2001, I received the following networked email message from Greening Australia (Queensland branch), a non-government organisation that has received funding from the Australian government to be the main adviser to community groups on issues involving vegetation management and revegetation. "Dear Carla, Do you want to learn how to increase the biodiversity of your local area? Join us .... for a workshop on 'Creating wildlife friendly gardens'. (Our) trainer will show participants how to attract and provide a home for native flora and fauna in your own backyard. It's easy to feel helpless in stopping the destruction of natural ecosystems. Yet through creating your own wildlife friendly garden and encouraging others, you can make a difference!".

Evidence about whether native birds prefer to feed on native plants is mixed (Green et al. 1989). Habitat recreation based on the assumption that installing individual plants of indigenous species will provide resources useful to native forest birds ignores two crucial ecological issues. Both involve the role of spatial structure of habitats. First, the presence of local physical structure and complexity is essential to provide substrates for moving, foraging, resting, breeding, and avoiding predators, that suit the morphology and behaviour of particular bird species (Weins 1989; Recher 1991). The combined architectural forms of different plant species and ages growing together in a forest creates a complex layered structure that is an important characteristic of forest habitats. Individual plants growing in isolation, or in a widely placed planting, do not provide the kind of structure required by many bird species that typically inhabit forests (Catterall et al. 1989; Sewell and Catterall 1998).

Second, individual animals require a patch of habitat that meets all their requirements for living on a daily, seasonal or annual basis, including sufficient area to provide food and other essential resources in the long-term (Weins 1989; Recher 1991). The size and nature of this patch will depend on the type of species involved, and also on its ability to move rapidly between patches. Furthermore, the longer-term persistence of a species in an area may depend on the maintenance of a breeding population, which means that the seasonal or annual requirements of many individuals must be catered for. This also raises the complex question of what might constitute a viable population size, over what area.

Within a typical home garden or small park, it is possible, with careful effort, to create a complex local threedimensional vegetation structure by clustering many plants of different species and life forms (Pizzey 1991), but it is not possible to provide habitat patch sizes even as small as one hectare. Conservation of pocket-handkerchief bushland remnants of one or two hectares, and planting-up of individual allotments or small land parcels both result in very small habitat patches, whose value to wildlife may be limited (Catterall et al. 1997a; Evans et al. 1997; Hudson et al. 1997; Sewell and Catterall 1998; Martin and Catterall 2001). An aggressive native honeyeater, the noisy miner Manorina melanocephala, may also play a significant role in limiting the use of these areas by small-bodied native birds (Low 1994; Sewell and Catterall 1998; Catterall et al. 2002).

The present paper aims to critically assess the extent to which well-intentioned planting has been able to achieve useful biodiversity outcomes for birds of the greater Brisbane region, to consider the ecological processes involved, and to comment on social implications. The paper re-analyses the combined data from a number of field studies, and reconsiders the findings of these and other related studies. The Brisbane region resembles much of the subtropical eastern Australian coastal lowlands, in its bird species, plant species, and major habitat types, and also because the past two decades have seen very rapid human population growth, accompanied by clearing of indigenous forest and woodland ("bushland") to make way for suburban residential development (Catterall and Kingston 1993a,b; Catterall et al. 1997b). It might, therefore, be expected that many of the patterns and phenomena reported in this paper will also occur in the remainder of eastern Australia's urbanising subtropics.

\section{Methods}

\section{Study region and its avifauna}

The Brisbane region and its lowland (around zero to $160 \mathrm{~m}$ amsl) habitats and avifauna relevant to the present paper have been described in Catterall et al. (1991), Catterall and Kingston (1993a, b), Ryan (1995), Catterall et al. (1997b; 1998) and Sewell and Catterall (1998). During the years of the present study, the region's suburban areas included some 
suburbs that were dominated by "traditional" gardens based on lawns and low-growing ornamental plants (such as rose bushes and clipped hedges), some that had a leafy cover of low trees among which introduced species of subtropical or tropical origin were predominant, and others that had a taller tree cover of sparse eucalypts (resulting mainly from partial retention of original trees when bushland areas were cleared for development), with nectar-rich native Grevillea cultivars frequently planted (see Catterall et al. 1991; Sewell and Catterall 1998 for further descriptions).

Additionally, the broader habitat mosaic of the urbanised region contained substantial grassy areas with scattered eucalypts or introduced tree species (parklands, golf courses, or remnant grassy pastures), and many remnant patches of intact native eucalypt forest or advanced eucalypt regrowth, varying in size (Catterall and Kingston 1993a,b). Less extensive land cover types included construction-dominated industrial and commercial precincts, "rural residential" developments that were a fine patchwork of clearings and remnant bushland, and small areas of remnant rainforest and melaleuca forest.

Upland parts of the region remain relatively undeveloped, and support extensive tracts of native forest, however, their vegetation and avifauna differ in many respects from those of the lowlands (Catterall and Kingston 1993a,b; Catterall et al. 1997a,b). In the lowland eucalypt forests and woodlands there are large seasonal differences in bird species' composition and density, due to seasonal movement patterns of many species (Catterall and Kingston 1993b; Park 1994; Catterall et al. 1998). Consequently, the local avifauna includes species that are winter immigrants (mainly from the south), others that are summer immigrants (from the north), and some that are seen mainly in passage north or south. In contrast, suburban habitats show little seasonal turnover in avifauna, since most migrant species are confined to forest remnants (Catterall et al. 1998).

\section{Study sites and bird data}

This paper presents a synthesis of data collected during six different projects that investigated the ecology of the region's lowland bird assemblages between 1986 and 1996 (Table 1). These studies were chosen, from a larger number available, on the basis that each included at least eight replicate sites within each of several different land cover types. Birds were visually surveyed in each using similar methods, during three visits in two different seasons or years (in all but one case this was summer and winter). Some aspects of these studies' results have been reported elsewhere (Table 1; see also Catterall et al. 1997a; Catterall et al. 2002).

Table I. Characteristics of the studies and data used in this paper. Each combination of study and land cover type is termed a "case" in the text.

\begin{tabular}{|c|c|c|c|c|}
\hline $\begin{array}{l}\text { Study, year of data collection }{ }^{1} \\
\text { and reference }\end{array}$ & Broad land cover type ${ }^{2}$ & Further details & $\mathrm{N}^{3}$ & $\begin{array}{l}\text { Abbreviation } \\
\text { (used in Figures) }\end{array}$ \\
\hline $\begin{array}{l}\text { Catterall, Green and Jones 1985-86 } \\
\text { (Catterall et al. 1991) }\end{array}$ & Suburbs & $\begin{array}{l}\text { Bare - few trees or } \\
\text { large shrubs }\end{array}$ & 16 & bareC86 \\
\hline \multirow{5}{*}{$\begin{array}{l}\text { Sewell 1991-92 (Sewell, 1992; Sewell } \\
\text { and Catterall 1998; Catterall et al. 1998) }\end{array}$} & Suburbs & $\begin{array}{l}\text { Bare - few trees or } \\
\text { large shrubs }\end{array}$ & 20 & bares9l \\
\hline & Suburbs & $\begin{array}{l}\text { Densely planted } \\
\text { after clearing }\end{array}$ & 20 & plantedS9| \\
\hline & Suburbs & $\begin{array}{l}\text { Planted gardens below } \\
\text { thinned original trees }\end{array}$ & 17 & canopys9l \\
\hline & Small bushlots & $5-10$ ha & 19 & 5-IOhaS9| \\
\hline & Bushland tracts & $>100 \mathrm{ha}$ & 20 & bushS9| \\
\hline \multirow{2}{*}{$\begin{array}{l}\text { Catterall, Kingston and Park 199|-92 } \\
\text { (Catterall et al. 1998) }\end{array}$} & Small bushlots & 10-20 ha & 20 & |0-20haC9| \\
\hline & Bushland tracts & $>400$ ha & 18 & bushC9I \\
\hline \multirow{2}{*}{$\begin{array}{l}\text { Bentley 1992-93 (Bentley 1994; Bentley } \\
\text { and Catterall 1997) }\end{array}$} & Bushland tracts & $\begin{array}{l}>300 \text { ha; sites away } \\
\text { from riparian areas }\end{array}$ & 20 & bushBd92 \\
\hline & Bushland tracts & $\begin{array}{l}>300 \text { ha; sites along } \\
\text { riparian areas }\end{array}$ & 20 & bushBr92 \\
\hline Park 1993-94 (Park 1994) & Bushland tracts & $>200 \mathrm{ha}$ & 10 & bushP93 \\
\hline \multirow{5}{*}{ Oertel 1996-97 (Oertel 1998) } & Suburbs/parkland & $\begin{array}{l}\text { Vegetated suburbs } \\
\text { and urban parks }\end{array}$ & 8 & vegsub○96 \\
\hline & Small bushlots & I-2 ha & 8 & I-2haO96 \\
\hline & Small bushlots & 4-10 ha4 & $16^{4}$ & 4-IOhaO96 \\
\hline & Small bushlots & I5-20 ha & 8 & I5-20haO96 \\
\hline & Bushland tracts & $>500$ ha & 8 & bush○96 \\
\hline
\end{tabular}

'Data were from a successive winter and summer, except Catterall, Green and Jones' 1985/86 data were from two successive winters (suburbs show little seasonal turnover).

2Minimum habitat area for a site was 20 ha, except for small bushlots.

${ }^{3} \mathrm{No}$. of replicate sites; these were usually separated by $>1 \mathrm{~km}$, and each was always sampled using a single transect 100 by 30 $\mathrm{m}$, visited on six mornings (three per season). Visit duration was 15 minutes except Oertel 1996/97 used 20 minutes.

${ }^{4}$ Comprised eight sites of 4-6 ha and eight of 8-10 ha. 
All studies used quantitative visual surveys of relative density to investigate differences in bird species composition and abundance between different predetermined habitats (land cover types). The different habitat types were always spatially interspersed with one another so that statistical comparisons between habitats should detect differences due to site type, rather than those associated with spatial variation. Bird surveys comprised a count of the number of individuals of each species seen within three repeat 15 or 20-minute visits to a small-scale transect $(100 \mathrm{~m}$ by 30 $\mathrm{m})$, repeated in winter (May-July) and summer (NovemberJanuary). Thus, the total time spent by an observer at each site was 1.5 to 2.0 hours. For analyses, abundance was scored as the sum of all sightings of a species over the six visits, and species richness was the total number of species recorded.

The present paper focuses on four different habitat (land cover) types (Table 1) that were drawn from the wider range available in each study. These are: (1) bare suburbs (few trees, extensive grassy areas; two cases, which contributed 36 replicate sites in total), (2) suburbs that were well vegetated (with introduced or native trees; two cases with 37 sites in total), (3) small bushland remnants ("bushlots"; with controlled size variation, from 1-2 to 15 20 ha; five cases with 71 sites in total), and (4) large forest tracts (several hundred ha or more; six cases with 96 sites in total). Additionally, one case that incorporated both wellvegetated suburbs and parkland (8 sites) was used in some analyses. The total number of site-surveys was thus 248, of which 212 took place in well-vegetated habitat types which varied in vegetation structure (foliage height, density), plant species composition, and patch size (area over which the forest habitat extended). Studies were only included if I was confident that each replicate site was embedded within a larger area (more than 20 ha of similar habitat) to exclude strong patch size effects, except in cases that aimed to assess the effect of size variation in small bushland remnants.

\section{Results}

\section{Response of avifauna to deforestation and urbanisation}

Based on previous research into urban avifauna (see Introduction), I selected three summary indicators to compare the bird assemblages of the main land cover types of the Brisbane region habitat mosaic. These are: the number of exotic species, the number of species as least as large as the noisy miner (63 g), and the number of species smaller than the noisy miner (Figure 1a).
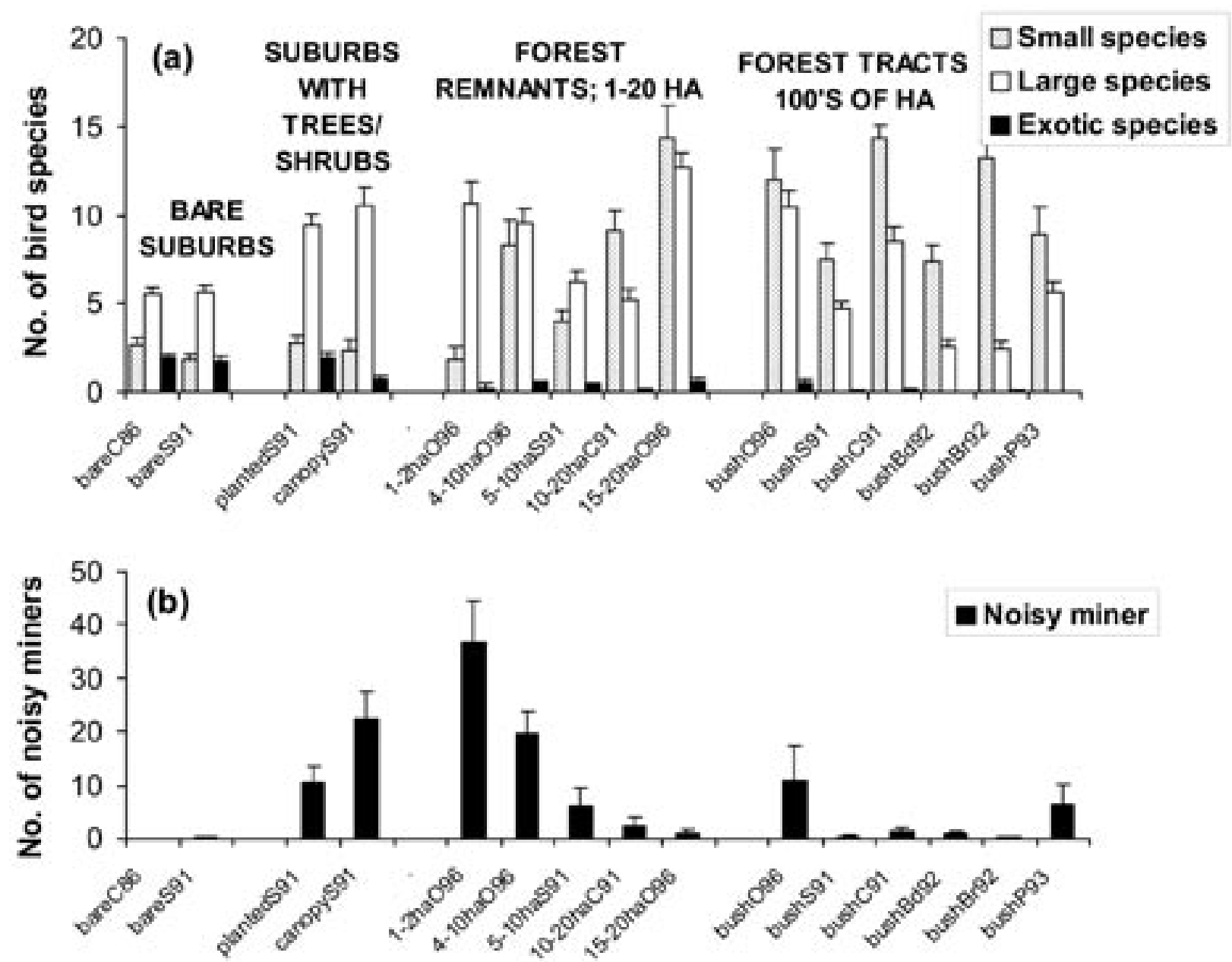

Figure I. Indicators of the avifauna for 15 study/land cover combinations (cases) in the Brisbane region (see Table I; minus the suburbs/parkland case). (a) Bird species richness by body size (above or below $63 \mathrm{~g}$ ) and origin (exotic species), size categories include exotic species; four broad habitat types shown in upper case. (b) Abundance of noisy miners. Data are the total number of species or birds (noisy miners) recorded during six, 15-20 minute visual observations in $100 \times 30$ m. Bars are standard errors. 
Suburban sites typically contained a few exotic species, with an average of about two species seen in 0.3 ha in 1.5 hours recorded in three of the four suburban cases (Figure 1a). Exotic species were slightly less common (about one seen on average) in the suburbs established below thinned original trees. In contrast, they were absent, or very rare, in most large forest tracts, and were rare (about 0.5 species on average) in urban bushlots, even those as small as one hectare in size.

The numbers of large-bodied species within large forest tracts varied considerably among the six different cases (3-10 recorded on average), but overall did not differ greatly from the numbers of large-bodied species recorded in suburbs, or in urban bushlots (Figure 1a), although there tended to be more in well-planted suburbs and bushlots than in either unvegetated suburbs or forest tracts.

Forest tracts contained a consistently high diversity of small-bodied species (averages ranged from 7-12; Figure 1a), and most of these species were absent from suburbs, irrespective of how well vegetated they were. Smallbodied species recorded in the suburbs were seen much less frequently (average of 1-3, these included both exotic and native birds). The numbers of small-bodied species in bushlots above 10 ha in area $(9,14$ species) were similar to those in forest tracts, but there was some decrease in bushlots below 10 ha, and small-bodied species were relatively scarce (around two species) in bushlots 1-2 ha in area.

Clearing and urbanisation, if unaccompanied by much planting of trees and shrubs, was associated with a large reduction in the number of small-bodied species, and a minor increase in the number of introduced species. Suburbs that were better-vegetated did not re-acquire small-bodied native species, but rather tended to show an increase in numbers of large-bodied species. The most common category in all types of suburb was large-bodied native species, whereas small-bodied natives were the most common category in all forest studies, as well as in remnant bushlots above 10 ha in size. Remnant bushlots of $1-2$ ha resembled the better-vegetated suburbs, whereas those between five and ten hectares in size were intermediate, tending to be dominated by large-bodied species, but also containing many small species (Figure 1a).

Noisy miners were virtually absent from poorly vegetated suburbs, and were generally also rare to uncommon in large forest tracts (Figure 1b). In well-vegetated land cover types their abundance tended to show a complementary pattern to that seen in small-bodied species (Figure 1b). Noisy miners showed a greatly elevated abundance in well-vegetated suburbs and smaller bushlots (below 10 ha).

Across all 212 well-vegetated sites there was a strong negative correlation between the abundance of noisy miners and the number of small-bodied species (Figure 2a). Some sites had few noisy miners and also few smallbodied species, but sites with many noisy miners never had more than about 5-6 small-bodied species, whereas sites with few or no noisy miners commonly had 10-15 small-bodied species.
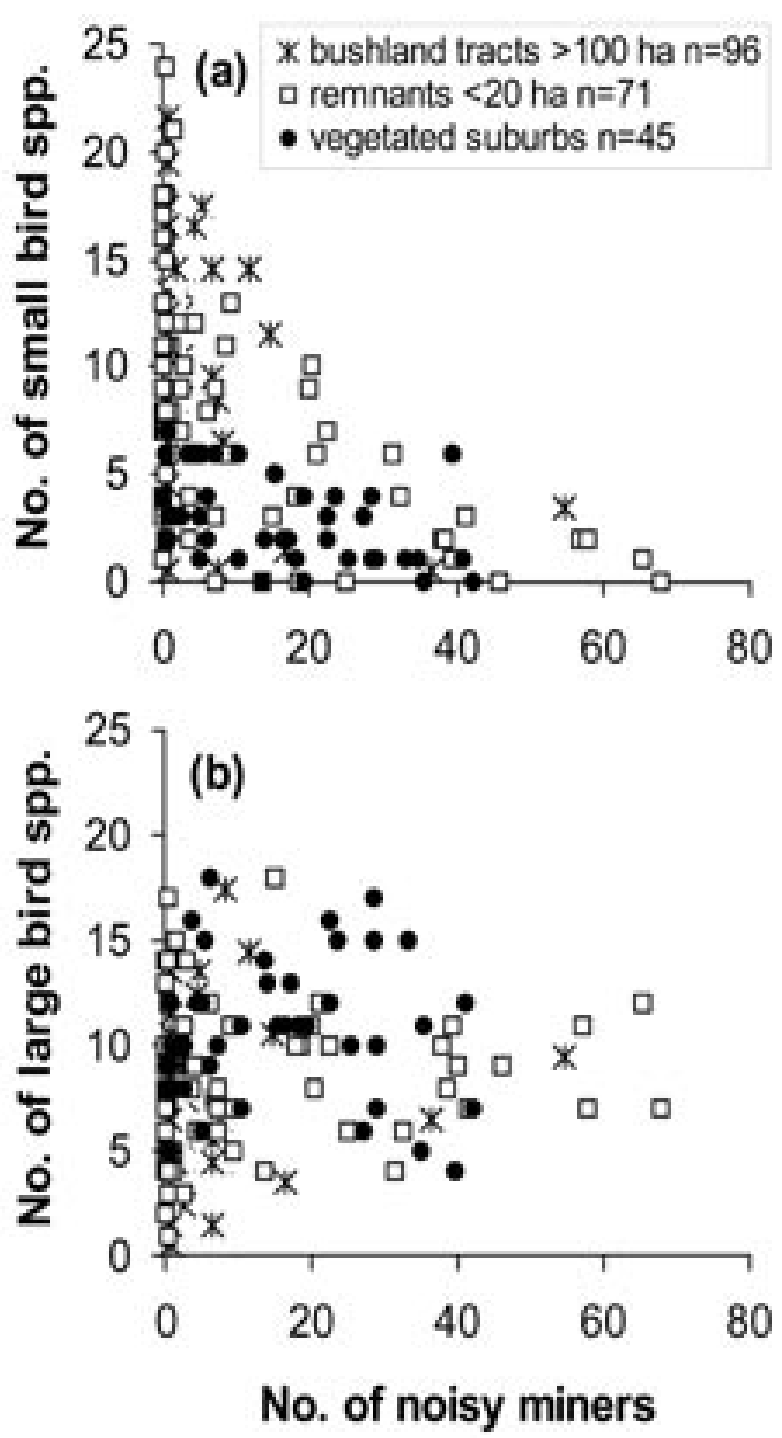

Figure 2. The relationship between the abundance of noisy miners and the species richness of (a) small birds (less than 63 g; Pearson's $r=-0.50, P<0.01$ ) and (b) large birds (63 g or more; Pearson's $r=0.27, P<0.0 \mathrm{I}$ ), across 212 vegetated sites spanning different styles and levels of vegetation cover (see Table I for details), in the Brisbane region lowlands. Data for each point are the total number of species (for each body size category) or birds (noisy miners) recorded during six, 15-20 minute visual observations in $100 \times 30 \mathrm{~m}$.

In contrast, there was a positive correlation between the abundance of noisy miners and the number of large-bodied species (Figure 2b), although the strength of association was less. The negative relationship between noisy miner abundance and the richness of small-bodied species is also seen when the sites are considered separately within each major land cover type (large forest tracts, bushlots, and suburbs/parkland; Figure 3). Even within the specific individual cases of small $(<10$ ha) bushlots and gardens planted below original eucalypt trees ("canopy suburbs"), high noisy miner abundance was also negatively associated with numbers of small bird species. 


\section{Individual species' responses}

To identify the common and characteristic species that were associated with these differences, the source data were further analysed for differences in abundance of individual species. In these analyses I considered only sites within the following three habitat categories (Table 2): unvegetated suburbs (representing the extreme of unfavourable urban habitat, two cases available); large forest tracts (representing the undeveloped state, three cases selected); and a mixed category of well-vegetated suburb and 1-2 ha bushlots (three cases available, representing attempts at vegetation replacement or retention that has been accompanied by elevated noisy miner abundance and the presence of many largebodied species but few small-bodied species). Only three of the six forest tract cases were used, to provide a balanced and logistically tractable level of comparison, based on large sample size (in each of the selected cases, birds were surveyed at 20 replicate sites), and also incorporating an explicit contrast between riparian and upslope forest, so as to encompass an important aspect of the known internal variation within native forest.

Table 2. Bird species characteristic of well-planted suburbs and small suburban bushlots, compared with bare suburbs, and intact forest within the Brisbane region. Shaded cells show species recorded from at least $40 \%$ of sites in two or more cases within each land cover type.

\begin{tabular}{|c|c|c|c|c|c|c|c|c|c|c|c|}
\hline \multirow{3}{*}{$\begin{array}{l}\text { Species at }>=40 \% \text { of sites, } \\
\text { (shown by } X \text { for each case) }\end{array}$} & \multicolumn{10}{|c|}{ Broad land cover type: } & \\
\hline & \multirow[b]{2}{*}{$\mathrm{O}^{2}$} & \multirow[b]{2}{*}{$\mathrm{B}^{2}$} & \multicolumn{2}{|c|}{ Bare suburbs ${ }^{3}$} & \multicolumn{3}{|c|}{$\begin{array}{c}\text { Vegetated suburb/ small } \\
\text { patch }^{4}\end{array}$} & \multicolumn{3}{|c|}{$\begin{array}{c}\text { Bushland tract } \\
>100 \mathrm{ha}^{5}\end{array}$} & \multirow{2}{*}{ Family } \\
\hline & & & C 86 & 591 & ps91 & cs91 & vsr96 & rb92 & $\mathrm{db} 92$ & $\mathrm{db} 9 \mathrm{I}$ & \\
\hline Willy Wagtail & & $\mathrm{S}$ & $x$ & $x$ & $x$ & & & & & & Dicruridae \\
\hline House Sparrow & $E$ & $\mathrm{~S}$ & $x$ & $x$ & $x$ & & & & & & Passeridae \\
\hline Common Starling & E & L & $x$ & $x$ & $x$ & & & & & & Sturnidae \\
\hline Spotted Turtle-Dove & $E$ & $\mathrm{~L}$ & $x$ & $x$ & $x$ & $x$ & & & & & Columbidae \\
\hline Magpie-lark & & $\mathrm{L}$ & $x$ & $x$ & $x$ & $x$ & & & & & Dicruridae \\
\hline Black-faced Cuckoo-shrike & & $\mathrm{L}$ & $x$ & $x$ & $x$ & $x$ & $x$ & & & $x$ & Campephagidae \\
\hline Grey Butcherbird & & $\mathrm{L}$ & & & $x$ & $x$ & $x$ & & & & Artamidae \\
\hline Australian Magpie & & $\mathrm{L}$ & & $x$ & $x$ & $x$ & $x$ & & & & Artamidae \\
\hline Torresian Crow & & $\mathrm{L}$ & $x$ & & $x$ & & $x$ & & & $x$ & Corvidae \\
\hline Rainbow Lorikeet & & $\mathrm{L}$ & & & $x$ & $x$ & $x$ & & & $x$ & Psittacidae \\
\hline Scaly-breasted Lorikeet & & $\mathrm{L}$ & & & $x$ & $x$ & $x$ & & & & Psittacidae \\
\hline Pale-headed Rosella & & $\mathrm{L}$ & & $x$ & $x$ & $x$ & $x$ & & & & Psittacidae \\
\hline Laughing Kookaburra & & $\mathrm{L}$ & & & $x$ & $x$ & $x$ & & & $x$ & Halcyonidae \\
\hline Noisy Friarbird & & $\mathrm{L}$ & & & $x$ & $x$ & $x$ & & & $x$ & Meliphagidae \\
\hline Noisy Miner & & & & & $x$ & $x$ & $x$ & & & & Meliphagidae \\
\hline Striated Pardalote & & $\mathrm{S}$ & & & & & & $x$ & $x$ & $x$ & Pardalotidae \\
\hline Yellow-faced Honeyeater & & $\mathrm{S}$ & & & & & & $x$ & $x$ & $x$ & Meliphagidae \\
\hline White-throated Honeyeater & & $\mathrm{S}$ & & & & & & $x$ & $x$ & $x$ & Meliphagidae \\
\hline Scarlet Honeyeater & & $S$ & & & & & & $x$ & & $x$ & Meliphagidae \\
\hline Golden Whistler & & $\mathrm{S}$ & & & & & & $x$ & $x$ & $x$ & Pachycephalidae \\
\hline Rufous Whistler & & $\mathrm{S}$ & & & & & & & $x$ & $x$ & Pachycephalidae \\
\hline Grey Shrike-thrush & & $\mathrm{S}$ & & & & & & $x$ & $x$ & $x$ & Pachycephalidae \\
\hline Grey Fantail & & $\mathrm{S}$ & & & & & & $x$ & $x$ & $x$ & Dicruridae \\
\hline Silvereye & & $\mathrm{S}$ & $x$ & & $x$ & & & $x$ & & & Zosteropidae \\
\hline
\end{tabular}

ISpecies common in only one case are not shown.

20 origin (E indicates exotic species); B body size ( $\mathrm{S}<63 \mathrm{~g}, \mathrm{~L}>=63 \mathrm{~g}$ ).

${ }^{3} \mathrm{C} 86, \mathrm{~S} 9 \mathrm{I}$ correspond to two cases of bare suburbs listed in Table I.

${ }^{4} \mathrm{ps} 9$ ।, cs9 I are respectively densely planted suburbs, and those planted beneath thinned canopy trees in Sewell 199।/ 92 data; vsr are remnant bushlots I-2 ha in Oertel 1996/97 data.

5rb92, db92 are riparian and upslope sites respectively in Bentley 1992/93 data; db91 are also upslope sites, from Sewell 199|/92 data. 

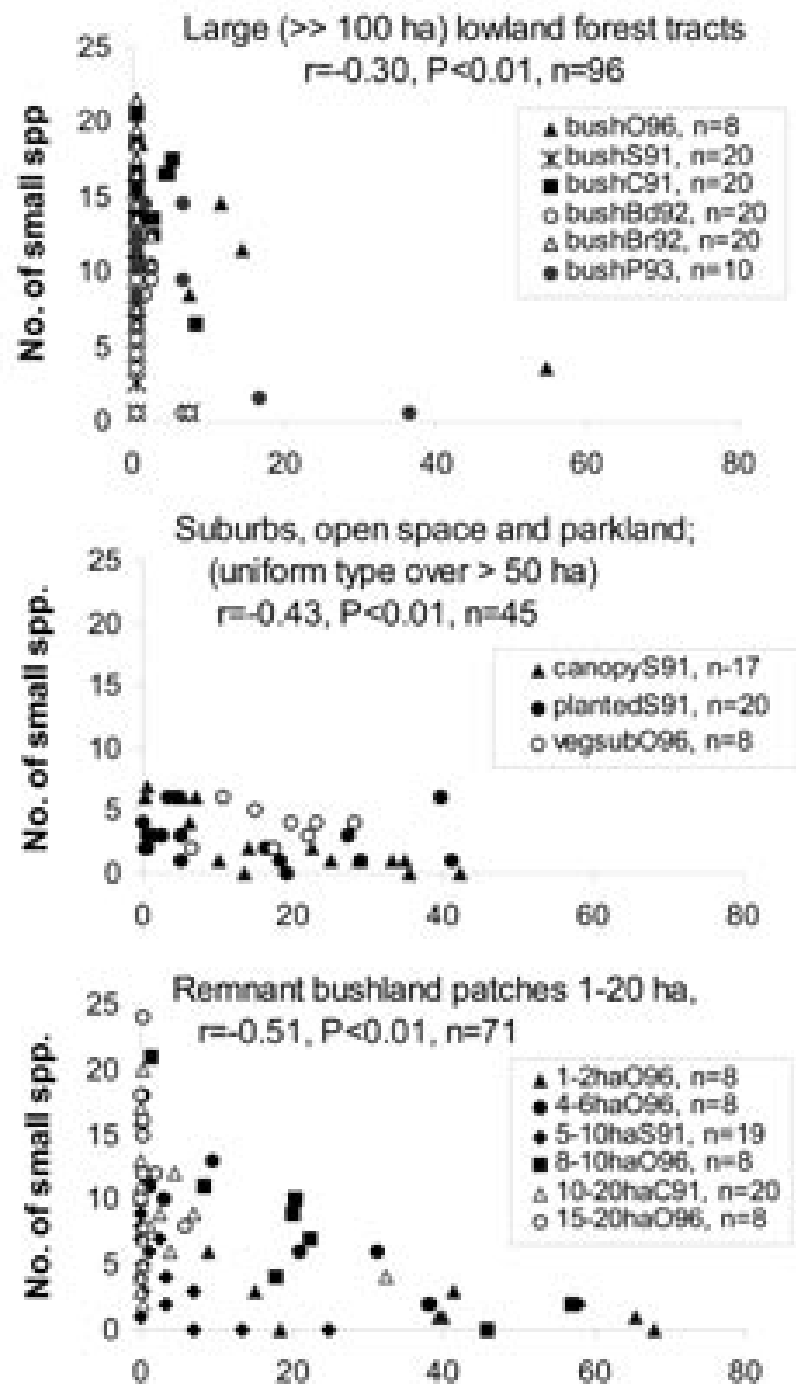

No. of noisy miners

Figure 3. The relationship between the abundance of noisy miners and the species richness of small birds (less than $63 \mathrm{~g}$ ), within each of three land cover types (large forest tracts, well-vegetated suburbs and parks, small remnant urban bushlots, details in Table I) in the Brisbane region lowlands. Data for each point are the total number of species or birds (noisy miners) recorded during six, I520 minute visual observations in $100 \times 30 \mathrm{~m}$.

For each of the eight cases, I calculated the per cent frequency of occurrence (the number of sites where a species was present as a proportion of the total sites surveyed) of all bird species recorded. A species was defined as "common" within each case if it had been recorded in at least $40 \%$ of sites. Table 2 shows the 24 species that were "common" in at least two of the eight cases, ordered so that species with similar patterns of occurrence across habitat types are grouped, and with those species that were "common" in at least two cases within a habitat type highlighted.

There were eight bird species that occurred commonly (present at many sites) in at least two case studies of bushland tracts, and all were uncommon in bare suburbs. There were six species characteristic of bare suburbs, and these were not common in forest (Table 2). Less predictably, the well-vegetated suburbs and 1-2 ha bushlots also shared few common, characteristic species with either the bare suburbs or the forest tracts (Table 2). These sites had a third suite of 12 common species, three of which were also characteristic of the bare suburbs, but none of which were consistently common in forest tracts.

The common forest species were all small-bodied Australian natives, with a strong representation from two families: the Meliphagidae (honeyeaters) and Pachycephalidae (whistlers, shrike-thrushes). The six common suburban species included three exotics, and comprised a mix of small- and large-bodied birds from six different families. The birds that characterised well-vegetated suburbs and 1-2 ha bushlots were mainly large-bodied indigenous species, with the families Artamidae (magpies, butcherbirds), Psittacidae (parrots) and Meliphagidae (honeyeaters) well represented. Thus, while tree planting or the retention of extremely small forest patches has encouraged a variety of native Australian birds, these are not the common indigenous bushland species.

\section{Discussion}

\section{Does urban tree planting enhance avian biodiversity?}

Previous investigations of patterns in suburban avifauna have frequently drawn conclusions from intensive data collection at one or a few study locations. In such cases, the generality of the results is unclear. The results presented here were based on a number of different studies, with a large number of spatially separate replicate study sites used in each. Furthermore, the data would have been affected by variation in many aspects of the six different studies, including: site observation time (20 minutes in the Oertel 1996/97 data set, but 15 minutes in the others); observer experience and idiosyncracy; particular detailed environmental criteria used in site selection; and years of data collection. All these factors would increase the background "noise" in the data set. The main results discussed here are general phenomena of sufficient magnitude to override the effects of these other factors, and which occur predictably in spite of natural background variability in space and time.

The findings of these research projects into the avifaunas of the Brisbane region habitat mosaic confirm that, while specimen-based garden or parkland planting will add trees, it does not create anything like a forest habitat (even when the planted specimens are Australian natives). Well-planted garden suburbs may support more large-bodied native bird species, such as magpies, butcherbirds, rosellas, lorikeets and noisy miners, but they fail to acquire the rich variety of common small-bodied species that characterise forest areas.

However, the native large-bodied birds of the wellvegetated suburbs are valued by many people and, as a group, these birds are generally known and appreciated by Australians who may otherwise have little interest in natural history. Collectively, they could be termed "Aussi 
Icon" species (Table 3). Their large size, ground-feeding habits, willingness to consume human food scraps, and tendency to become tame and interactive with people when fed regularly, make them a much-appreciated part of the urban landscape. A perception of their indigenous origin also encourages many people to appreciate, rather than disdain, them. Aussi Icons have become prominent in white Australian folklore, perhaps because many of these species are tolerant of forest thinning, fragmentation, and understorey loss in rural areas throughout their broad geographical ranges (Loyn 1987; Catterall et al. 1998).

These birds are much scarcer in suburbs without much vegetation, where there is typically a limited avifauna of "New Arrivals" (Table 3), comprising a smaller number of less appreciated species, three of which (sparrows, starlings, turtle-doves) arrived from overseas with the European settlers. House sparrows and common starlings are also considered to be pests in some situations. The other two New Arrivals (willy wagtail, magpie-lark) are native species that have increased in numbers and moved into new areas following tree-clearing and European landuses (Blakers et al. 1984; Catterall et al. 1998).

In contrast, the common avifauna of indigenous intact eucalypt forest and woodlands is dominated by a high abundance and diversity of small-bodied species that feed on insects and/or nectar near the foliage of trees and shrubs. Many belong to a suite of predominantly Australian bird genera and families. The majority of these birds are intolerant of forest clearing, thinning, and fragmentation (Loyn 1987; Catterall et al. 1991, 1998). Due to their small size, often rapid movement patterns, reclusive foliage-attached nature, and frequently cryptic colouration, they are not easily noticed by casual observers. Furthermore, their attachment to intact forest habitat makes it unlikely that they would be much seen by inhabitants of urban or rural areas unless actively sought out during walks in remnant bushland. Due to their insectivorous and nectarivorous habits, this group potentially provides ecologically beneficial environmental services of insect pest control and pollination. These are the "Neglected Foliphiles" (Table 3). A well-informed conservation-oriented naturalist would be relatively unimpressed by the Aussi Icons, and would place a much higher value on gardens that are frequented by the Neglected Foliphiles.

An individual well-planted garden adjacent to a large forest area may receive visits from such species, but this would be a consequence of its spatial context, and these birds would be very unlikely to visit such a garden if it were surrounded by others of the same type. Neither do they frequent residential developments that have been established beneath thinned original canopy eucalypts, or remnant patches of original bushland that are below about 2 ha in size (an area approximately $150 \mathrm{~m}$ square, or a circle of $80 \mathrm{~m}$ diameter). Small remnant bushlots tend to show these limitations to their avifaunal conservation values up to an area of around 5-10 ha (approximately 200-300 m square, or a circle of diameter 120-180 m). Planting of small urban strips and patches dominated by eucalypts, such as those encouraged by the Australian government's environmental initiatives during the latter part of the 1990s, may likewise be unlikely to provide useful habitat for many conservation-dependent birds.

Spatial issues of this type have until very recently (e.g. Low 2002) been overlooked and neglected by natural history writers, even those aware of the importance of local vegetation structure. It is likely that many naturalists acquire a biased and unrealistic view of potential garden fauna because they choose to live in houses adjacent to bushland. For example, Pizzey (1991) wrote lucidly about the importance of creating local vegetation complexity, and warned of the effects of noisy miners, but then proceeded to link the rich and enchanting avifauna of his rural home garden with the garden's characteristics alone, by implication discounting the important role of its location adjacent to a forest reserve.

Table 3. Major groups of common bird species in the Brisbane region, in relation to their response to land cover conversions of the late twentieth century (deforestation, urbanisation, and garden or parkland plantings).

\begin{tabular}{lll}
\hline Bird group & Ecological characteristics & Member species (see Table 2) \\
\hline Neglected Foliphiles & $\begin{array}{l}\text { Small bodied. } \\
\text { Typical of intact bushland patches greater than } \\
\text { I0-20 ha, with a well-developed understorey. }\end{array}$ & $\begin{array}{l}\text { Striated pardalote, yellow-faced honeyeater, } \\
\text { white-throated honeyeater, scarlet } \\
\text { honeyeater, golden whistler, rufous whistler, grey } \\
\text { shike-thrush, grey fantail. }\end{array}$ \\
\hline \multirow{2}{*}{ New Arrivals } & $\begin{array}{l}\text { Size variable. } \\
\text { Ground or aerial feeders. } \\
\text { Typical of poorly-vegetated suburbs. }\end{array}$ & $\begin{array}{l}\text { Willy wagtail, house sparrow, common starling, } \\
\text { spotted turtle-dove, magpie-lark. }\end{array}$ \\
\hline Aussi lcons & $\begin{array}{l}\text { Large-bodied. } \\
\text { Ground- or mixed feeders. } \\
\text { Typical of planted-up suburbs, and areas with } \\
\text { remnant trees and small bushland patches. }\end{array}$ & $\begin{array}{l}\text { Grey butcherbird, Australian magpie, Torresian } \\
\text { crow, rainbow lorikeet, scaly-breasted lorikeet, } \\
\text { pale-headed rosella, laughing kookaburra, } \\
\text { noisy friarbird. }\end{array}$ \\
\hline
\end{tabular}

Same habitat as Aussi Icons.

Terrorist Encouraged by scattered tall eucalypts or forest edges, and nectar-rich cultivars of

Noisy miner. Australian plant species. 


\section{The role of noisy miners}

The noisy miner plays an important role in aggravating the loss of small foliage-feeding birds from partly-vegetated areas (Loyn 1987; Catterall et al. 1991, 2002; Low 1994). This species occurs throughout temperate and subtropical eastern Australia (Blakers et al. 1984). Noisy miners use vigorous coordinated attacks, accompanied by loud strident vocalisations, to drive away animals that enter the group territory. Their targets include birds, mammals and reptiles, that sometimes are wounded or even killed (Dow 1977). Hence the noisy miner is labelled "Terrorist" in Table 3. The data presented in this paper show a consistent and strong negative correlation between noisy miner abundance and the number of smaller-bodied species using a site, and there is a considerable body of evidence that miner occupancy of sites is associated with local declines of other bird species, both in the Brisbane region (Catterall et al. 1991, 2002; Woodall 1996, 2002; Hudson et al. 1997; Piper and Catterall 2003) and elsewhere (e.g. Loyn 1987; Grey et al. 1998; Mac Nally et al. 2000; Major et al. 2001). The miners are very effective at excluding smaller-bodied species from their colonies, but appear to have little impact on larger-bodied birds (Catterall et al. 2002; Piper and Catterall 2003).

Noisy miners show elevated densities in response to thinning of the canopy, loss of understorey, conversion of continuous forest to small patches and edges, and the creation of sparse eucalypt tree cover through planting or natural regeneration (Catterall et al. 2002). The minerenhancing effect of a sparse eucalypt tree cover over an open understorey seems to be magnified in urban areas, apparently because plantings of nectar-bearing Australian native shrub cultivars provide additional food, resulting in extremely high miner densities (Sewell and Catterall, 1998; Catterall et al. 2002).

The widespread occupancy of such areas by a single aggressive species, and the consequent loss of many other species, while a commonly observed phenomenon in subtropical and temperate eastern Australia, is unusual on a global scale, and could not be predicted from ecological theory or prior knowledge of the biology and distribution of these birds in undisturbed habitat. Most of Australia's urban development, and most suburban gardens, occur within the noisy miner's range. Paradoxically, the planting of scattered eucalypts in urban gardens, and landscaping efforts that feature cultivars of native plants selectively bred for their persistent flowering and nectar-rich flowers, can have a somewhat different effect on a garden's bird diversity from that intended. These gardens may attract a moderate diversity of native birds, but these birds are noisy miners and Aussi Icons, rather than Foliphiles. The plantings do not provide habitat that off-sets the impacts of deforestation on forest birds.

Furthermore, noisy miners are increasing. There is anecdotal evidence that Hobart, Sydney, and Brisbane have all experienced increases in their numbers since European settlement (Hoskin et al. 1991; Low 2002). In Brisbane home gardens, their frequency of occurrence increased by $23 \%$, and their abundance by $100 \%$, during 1979-99 (Woodall 2002). Twelve other large species (all
$>80 \mathrm{~g}$, including rainbow and scaly-breasted lorikeets and crested pigeon) concurrently increased significantly in frequency, and one (common starling $75 \mathrm{~g}$ ) decreased significantly, as did six smaller-bodied species (all <60 g, including house sparrow, welcome swallow, rufous whistler, grey fantail, and striated pardalote). Over this period the percent of these gardens that were over 20 years old increased from $29 \%$ to $56 \%$, the mean number of large trees increased from 22 to 34 , the open space (usually lawn) in the gardens decreased from $44 \%$ to $40 \%$, the per cent that were adjacent to bushland decreased from $66 \%$ to $29 \%$, and there was a decrease in the frequency of cats and dogs. Woodall (2002) concluded that increases in noisy miner numbers were a probable cause of at least some of the declines in smaller-bodied species. In Canberra, noisy miner numbers remained low during 1981-89, becoming more stable in the late 1980 s, with breeding recorded only since 1988 (Veerman 2002), hinting that future increases may be likely. Across much of eastern Australia, both the Aussi Icons (or closely-related species) and the noisy miner appear to be expanding - in rural and new urban areas because of partial clearing, thinning and loss of understorey, and in older urban areas because of treeplanting with eucalypts and nectar-bearing shrubs.

However, noisy miner invasion appears to be a secondary cause of degradation rather than a primary threat, and Catterall et al. (2002) argued that enlightened planning and management of both the quantity and quality of remnant lowland forest cover at a regional scale, rather than active control of noisy miners, is the crucial conservation issue. An important exception to this may be small urban bushlots. Removal of miner colonies would be likely to result in increased numbers of the Neglected Foliphile species, which would in turn increase the potential for city-based Australians to encounter a full range of small native birds within their local vicinity (Catterall et al. 2002). These encounters provide an opportunity to gain an appreciation of the common indigenous forest-dependent avifauna. Amendment of State legislation would be needed, to reduce or remove the protection currently afforded to noisy miners, and thereby allow humane culling in appropriate situations.

It might also be argued that the chance of noisy miner occupancy could be reduced by designing the physical structure of gardens differently, for example, if a dense shrubby understorey and multi-layered foliage structure were achieved through careful planting. Eucalypt forest and woodland remnants in rural areas often lack an understorey due to grazing impacts, and restoring an understorey in such situations may be effective (Grey et al. 1998). However, because noisy miners occupy forest edges (Catterall et al. 1991; Green and Catterall 1998), this is only likely to be effective when the "forested" patch size is large enough to provide some "interior" habitat, which would require around 10 ha, since miners occupy an edge zone of 100-200 m (Piper and Catterall 2003). The planted patch size in a typical suburban garden can never be greater than a fraction of a hectare, and therefore in much of eastern Australia will be miner-suitable "edge" habitat, no matter how carefully it mimics the structure of a dense multi-layered forest. 


\section{Urban planning for bird diversity and conservation}

What are the implications of these findings for landuse planning in urban areas? First, it is important for planners, the nursery industry, and all those individuals and organisations that use tree-planting as a means of paying lip service to conservation goals, while simultaneously pursuing environmentally damaging developments, to "get real". This means recognising that the installation of individual Australian native trees or shrubs, or even the installation of small patches of trees and shrubs, will not contribute to the maintenance of conservation-dependent indigenous forest birds. There are two main reasons for this. First, such planted areas are prone to occupancy by noisy miners. Second, their habitat values per se are limited (see Introduction). Among the sites in Brisbane where noisy miners were absent, those in well-vegetated suburbs supported only a few small-bodied species (around five, Figure 3), whereas in remnant bushland patches 5-20 ha in area they averaged around 10 small-bodied species. Progress towards integrating conservation goals with urban planning requires more emphasis on establishing a minimum desirable per cent of a subcatchment or region that should be forested, and identifying minimum functional habitat patch sizes for various components of biological diversity (see also Ferrier et al. 1993; Anon. 1995).

Second, there are several public education challenges. The notion that planting individual Grevillea or other nectarbearing native plant cultivars in an urban garden is likely to attract a range of forest honeyeaters needs to be replaced by a greater awareness of the importance of the overall structure and area of a forest-like vegetation patch (Sewell and Catterall 1998, Catterall et al. 2002). Urban residents need interpretive materials that explain how native species, such as the noisy miner, can be an agent contributing to ecological dysfunction, and which provide more information on the opportunistic nature of the Aussi Icon species, and the qualities of the Neglected Foliphiles. Landcare groups in temperate and subtropical eastern Australia need to develop an awareness that, if plantings are small, have a high ratio of edge to area, and have widely scattered trees that are mainly eucalypts, they may be colonised by noisy miners once the eucalypts have become sufficiently tall.

Third, it is also acknowledged that a suburb of Aussi Icons has its own unique values, and in environmental terms, it is a quantum leap better than a bare suburb of lawn and ornamental shrubs. Furthermore, scattered and sparse trees within urban environments have other social and aesthetic values and may be useful to other conservationdependent organisms (such as certain native insects). Likewise, small bushlots have values other than those associated with conserving forest-dependent avifauna. But the likely limitations to their avifaunal values also need to be acknowledged, together with a greater recognition of their important role in public education about environmental issues and processes.

We need to gain a more sophisticated view of the shades and levels of species-mix and types of value associated with the differing types of modified habitat in disturbed, human-dominated areas. The ecological concept of betadiversity, between-habitat variation in species composition (Weins 1989), when applied to the "naturalness" of habitat types in an urban mosaic, deserves a fuller airing. In this sense, a rich and vibrant urban mosaic would include some areas dominated by cement or lawn, some with Grevillea-rich Aussi Icon gardens, and others with sufficiently large and linked patches and corridors of urban bushland that support the heritage-valued avian Foliphiles. Patches and riparian corridors of non-eucalypt forest types, such as rainforest and melaleuca forest, can provide important fruit and nectar resources for birds, and are much less likely than eucalypt forest to be occupied by noisy miners (Catterall et al. 2002). These habitats support a somewhat different set of common bird species, which would contribute further to beta-diversity. The challenge for applied ecologists and urban planners is to incorporate ecologically sound patch sizes and spatial configurations into such a mosaic, and to be able to work at ecologically realistic and useful spatial scales. The challenge for everyone is to foster the political will to achieve it.

\section{Acknowledgements}

I thank Sven Sewell, Kate Park, Mark Kingston, Anne Oertel, Scott Piper, Joss Bentley, Ronda Green, and Darryl Jones for their various roles in generating the data sets analysed here. Discussions with them and many

others, including Scott Piper, have contributed to the development of themes and arguments pursued in this paper. Richard Major and Tim Low provided helpful comments on the manuscript.

\section{References}

Anon. 1995. Local Greening Plans. A Guide For Vegetation and Biodiversity Management. Greening Australia, Canberra.

Bentley, J.M. 1994. Bird Use of Bushland, Corridors, and Linear Remnants in South-east Queensland. B.Sc. Hons. Thesis, Griffith University: Brisbane.

Bentley, J.M. and Catterall, C.P. 1997. The use of bushland, corridors and linear remnants by birds in south east Queensland, Australia. Conservation Biology 11: 1173-89.

Blakers, M., Davies, S.J.J.F. and Reilly, P.N. 1984. The Atlas of Australian Birds. Melbourne University Press, Melbourne.

Catterall, C.P. 1991. On the importance of watching birds. Wildlife Australia 28: 3-5.

Catterall, C.P., Green, R.J., and Jones, D.N. 1989. The occurrence of birds in relation to plants in a subtropical city. Australian Wildlife Research 16: 289-305.

Catterall, C.P., Green, R.J., and Jones, D.N. 1991. Habitat use by birds across a forest-suburb interface in Brisbane: implications for corridors. Pp 247-58 in Nature Conservation 2, the Role of Corridors, edited by D.A. Saunders and R.H. Hobbs. Surrey Beatty and Sons, Chipping Norton. 
Catterall, C.P and Kingston, M. 1993a. Remnant Bushland of South East Queensland in the 1990's: its Distribution, Loss, Ecological Consequences and Future Prospects. Institute of Applied Environmental Research, Griffith University and Brisbane City Council. 97 pp.

Catterall, C.P. and Kingston, M. 1993b. Human populations, bushland distribution in south eastern Queensland and the implications for birds. Pp.105-22 in Birds and Their Habitats: Status and Conservation in Queensland, edited by C.P. Catterall, P. Driscoll, K. Hulsman, and A. Taplin. Queensland Ornithological Society, Brisbane.

Catterall, C.P., Kingston, M.B., and Park, K. 1997a. Use of remnant forest habitat by birds during winter in subtropical Australia: patterns and processes. Pacific Conservation Biology 3: $262-74$.

Catterall, C.P., Storey, R.J. and Kingston, M.B. 1997b. Reality versus rhetoric: a case study monitoring regional deforestation. Pp. 367-77 in Conservation Outside Nature Reserves, edited by P. Hale and D. Lamb. Centre for Conservation Biology, University of Queensland, Brisbane.

Catterall, C.P., Kingston, M.B., Park, K., and Sewell, S. 1998. Effects of clearing lowland eucalypt forests on a regional bird assemblage. Biological Conservation 84: 65-81.

Catterall, C.P. Piper, S., and Goodall, K. 2002. Noisy miner irruptions associated with land use by humans in south east Queensland: causes, effects and management implications. Pp. 117-127 in Landscape Health of Queensland, edited by A. Franks, J. Playford, \& A. Shapcott. Proceedings of the Royal Society of Queensland, Brisbane.

Dow, D.D. 1977. Indiscriminate interspecific aggression leading to almost sole occupancy of space by a single species of bird. Emu 77: $115-21$

Evans, R., Catterall, C.P. and Brumm, G.V. 1997. The habitat value of extremely small bushland remnants to birds in Brisbane. Sunbird 27: 38-44.

Ferrier, T., White, G. and Birbeck, J. 1993. Planning for bird conservation in urban Queensland. Pp.195-6 in Birds and Their Habitats: Status and Conservation in Queensland edited by C.P. Catterall, P. Driscoll, K. Hulsman, and A. Taplin. Queensland Ornithological Society, Brisbane.

Green, R.J. and Catterall, C.P. 1998. The effects of forest clearing and regeneration on the fauna of Wivenhoe Park, south east Queensland. Wildlife Research 25: 677-90.

Green, R.J., Catterall, C.P. and Jones, D.N. 1989. Foraging and other behaviour of birds in subtropical and temperate suburban habitats. Emu 89: 216-22.

Grey, M.J., Clarke, M.F. \& Loyn, R.H. 1998. Influence of the Noisy Miner Manorina melanocephala on avian diversity and abundance in remnant grey box woodland. Pacific Conservation Biology 4: 55-69.

Hoskin E.S., Hindwood, K.A. and McGill, A.R. 1991. The Birds of Sydney. Surrey Beatty and Sons Pty Ltd, Chipping Norton

Hudson, K., Catterall, C.P., McNamara, S. and Kingston, M.B. 1997. How useful are small but lightly treed suburban parks for forest birds in Brisbane? Sunbird 27: 57-64.

Mac Nally, R., Bennett, A. F. and Horrocks, G. 2000. Forecasting the impacts of habitat fragmentation. Evaluation of species-specific predictions of the impact of habitat fragmentation on birds in the box-ironbark forests of central Victoria, Australia. - Biological Conservation 95: 7-29.

Major, R., Christie, F.J. and Gowing, G. 2001. Influence of remnant and landscape attributes on Australian woodland bird communities. Biological Conservation 102: 47-66.

Martin, T.G. and Catterall, C.P. 2001. Do fragmented coastal heathlands have habitat value to birds in eastern Australia? Wildlife Research 28: 1-15.

Landsberg, J., Morton, S., and James, C. 1999. A comparison of the diversity and indicator potential of arthropods, vertebrates and plants in arid rangelands across Australia. Pp. 111-20 in The Other 99\%. The Conservation and Biodiversity of Invertebrates edited by W. Ponder and D. Lunney. Transactions of the Royal Zoological Society of New South Wales, Mosman.

Low, T. 1994. Invasion of the savage honeyeaters. ANH 24/10: $27-34$.

Low, T. 2002. The New Nature. Penguin Books: Camberwell.

Loyn, R. H. 1987. Effects of patch area and habitat on bird abundances, species numbers and tree health in fragmented Victorian forests. Pp 65-77 in Nature Conservation: The Role of Remnants of Native Vegetation edited by D. A. Saunders, G. W. Arnold, A. Burbidge and A. J. M. Hopkins. Surrey Beatty and Sons, Chipping Norton.

Oertel, A.S. 1998. Use of Small Eucalypt Forest Remnants by Birds in South East Queensland. B. Sc. (Hons) thesis, Griffith University, Brisbane.

Piper, S.D. and Catterall, C.P. 2003. A particular case and a general pattern: hyperaggressive behaviour by one species may mediate avifaunal decreases in fragmented Australian forests. Oikos 101: 602-14.

Park, K. 1994. Aspects of Migration and Residency in Birds of Eucalypt Forests in South-east Queensland. B.Sc. Hons. Thesis, Griffith University: Brisbane.

Pizzey, G. 1991. A Garden of Birds. Attracting Birds to Australian Gardens. HarperCollinsPublishers, North Ryde.

Recher, H. F. 1991. The conservation and management of eucalypt forest birds: resource requirements for nesting and foraging. Pp. 25-34 in Conservation of Australia's Forest Fauna edited by D. Lunney. Royal Zoological Society of New South Wales, Sydney.

Ryan, M. (ed.). 1995. Wildlife of Greater Brisbane. Queensland Museum, Brisbane.

Sewell, S and Catterall, C.P. 1998. Bushland modification and styles of urban development: their impacts on birds in south east Queensland. Wildlife Research 25: 41-64.

Weins, J.A. 1989. The Ecology of Bird Communities. Volumes 1 and 2. Cambridge University Press, Cambridge.

Woodall, P.F. 1996. Limits to the distribution of the House Sparrow Passer domesticus in suburban Brisbane, Australia. Ibis 138: 337-40.

Woodall, P.F. 2002. The Birds Queensland garden bird survey, 1999-2000. Sunbird 32: 37-51.

Veerman, P.A. 2002. Canberra Birds: a Report on the First 18 Years of the Garden Bird Survey. Canberra Ornithologists Group, Canberra. 